\title{
Numerical simulation of wind effects on an airport air traffic control tower
}

\author{
M. I. Farouk ${ }^{1}$, S. A. Mourad ${ }^{2}$ \& A. S. Salaheldin ${ }^{3}$ \\ ${ }^{1}$ Irrigation \& Hydraulic Structures Department, \\ Faculty of Engineering, Ain Shams University, Cairo, Egypt \\ ${ }^{2}$ Structural Engineering Department, Faculty of Engineering, \\ Cairo University, Cairo, Egypt \\ ${ }^{3}$ Structural Department, Dar Al-Handasah Consultants, \\ Shair and Partners, Egypt
}

\begin{abstract}
Determination of wind action on high structures with special importance presents a major challenge for civil engineers. Different methods are used to calculate the wind action; simplified method, analytical method, numerical method and experimental method. In this research a three-dimensional numerical model was developed using Computational Fluid Dynamics "CFD" software to study the wind action on a New Airport Air Traffic Control Tower. The tower is nearly $107 \mathrm{~m}$ high, comprises 15 ring beams and is located in an open area. The maximum wind speed used was based on the measured wind data for the structure location. The case study was solved as time-dependent, threedimensional and turbulent flow. A numerical simulation using 1.4 million hexahedral elements was developed. Pressure and viscous forces were determined on the entire tower and on each individual ring beam along the tower. The values and the locations of the maximum pressure and tension stresses were precisely specified. The results show that the maximum negative stresses (suction) are nearly twice the maximum positive stresses (pressure). In addition the forces and the moments acting on any ring beam calculated by the numerical simulation are nearly $65 \%$ less than those calculated by the code.

Keywords: computational fluid mechanics, wind exposure, numerical simulation of wind flow, control tower.
\end{abstract}




\section{Introduction}

The determination of wind action on structures is a critical issue in tall slender civil engineering structures. Wind effect represents an important load and cannot be neglected in the dimensioning of many structures. The effects of wind on structures are dependent on different factors including the building's shape, height and surroundings. Wind may lead to global collapse of the structures cause human discomfort for the building occupants. Therefore, the wind effects should be precisely determined and taken into consideration in the design of structures. Four different methods can be used to determine the wind loads as follows:

(1) Method 1 - Simplified procedure;

(2) Method 2 - Analytical procedure;

(3) Method 3 - Experimental procedure;

(4) Method 4-Numerical procedure.

The first two methods are used to determine the wind load from equations whereas the last two methods calculate the wind load from modeling. The experimental procedure is generally accomplished by using wind tunnel testing $[1,5]$. The numerical simulation is considered as an alternative solution of the wind tunnel study $[2-4,6]$.

In this research; a three-dimensional numerical simulation has been developed using CFD software Fluent [8] to study wind effects on the New Cairo Airport Air Traffic Control Tower. The effects include wind forces, stresses and moments. All the realistic conditions including the shape of the structure, the wind speed, the wind direction and the wind exposure are simulated. Since the terrain around the tower is flat and is generally opened for more than $0.8 \mathrm{~km}$ in any full quadrant, exposure $\mathrm{C}$ was selected for the wind distribution on different heights according to Uniform Building Code [9]. The problem was solved as three-dimensional unsteady turbulent and thus its simulation was significantly time consuming.

\section{Theoretical approach}

The mass conservation equation

$$
\frac{\phi p}{a}+\nabla \rho \vec{v}=S_{m}
$$

where

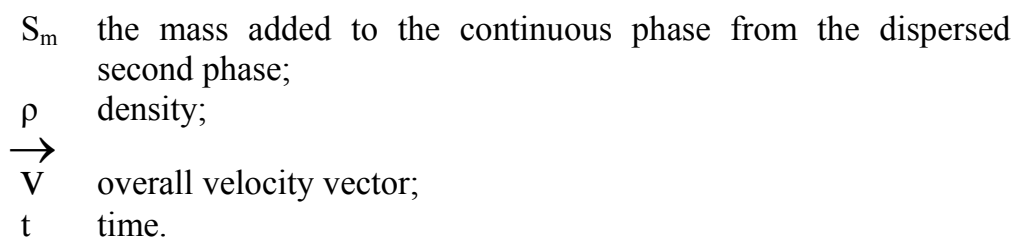

In the studied problem $S_{m}$ equals zero. 
Momentum conservation equation:

$$
\frac{\partial}{\partial}(\rho \vec{v})+\nabla \cdot(\rho \vec{v} \mathrm{v})=-\nabla \mathrm{P}+\nabla \cdot(\tau)+\rho \vec{g}+\overrightarrow{\mathrm{F}}
$$

where:

$$
\begin{array}{ll}
\mathrm{P} & \text { static pressure; } \\
\overline{\bar{\tau}} & \text { stress tensor; } \\
\mathrm{g} & \text { gravitational acceleration; } \\
\overrightarrow{\mathrm{F}} & \text { the external body forces. }
\end{array}
$$

In the studied problem $\mathrm{F}$ is assumed zero.

The turbulence intensity, $\mathrm{I}$, is defined as the ratio of the root-mean-square of the velocity fluctuations, $u \backslash$, to the mean velocity $u_{a v g}$.

where

$$
\mathrm{I}=\frac{\mathrm{u} \backslash}{\mathrm{u} \text { avg }}
$$

I the turbulence intensity;

$u^{\prime}$ the root-mean-square of the velocity fluctuations;

$\mathrm{u}_{\mathrm{avg}}$. the mean velocity.

A turbulence intensity of $1 \%$ is generally considered low and turbulence intensities greater than $10 \%$ are considered high. The studied problem was solved as a high turbulence.

The compressibility of air depends on the wind velocity relative to the speed of the sound, which is known as Mach number, $\mathrm{M}$

$$
\mathrm{M} \equiv \frac{\mathrm{u}}{\mathrm{c}}
$$

where

$$
\begin{array}{ll}
\text { c } & \text { speed of the sound; } \\
\mathrm{M} & \text { Mach number; } \\
\mathrm{u} & \text { wind speed. }
\end{array}
$$

When Mach number is less than 1.0, the flow is termed subsonic, at Mach numbers much less than 0.1 , compressibility effects are negligible and the variation of the gas density can be safely ignored, which is the case of the studied problem.

\section{Model development}

\subsection{Geometry and mesh}

The tower geometry was precisely simulated as shown in Figure 1. The mesh generation was carried out by Gambit Software [7]. The main objective of the mesh generation was to provide the appropriate size of different elements 
everywhere in the entire model, to prevent the creation of any inverted element and to decrease the skewness of the elements. The adaptation of the mesh was designed to get the best possible results in the minimum possible time, where the fine mesh is utilized for the elements on the structure, while the mesh becomes coarser as the elements are farther from the structure. The mesh comprised about 1.4 million hexahedral elements.

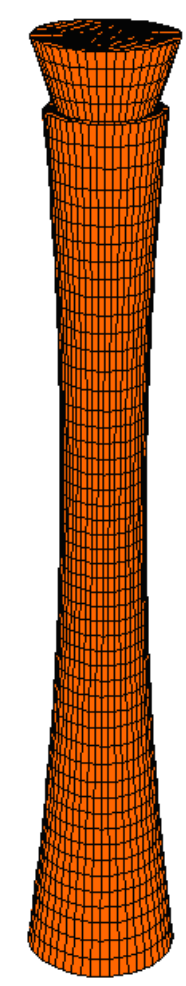

Figure 1: The mesh on the tower surface.

\subsection{The meteorological conditions:}

Based on the metrological data of the site, the magnitude of the mean hourly wind speed for 50 year return period was found to be to $50 \mathrm{mph}(22.5 \mathrm{~m} / \mathrm{s})$ at $10 \mathrm{~m}$ above ground in open terrain. The maximum wind speed was based on the measured wind data for the structure location. As the tower is located in a region with few and considerably low buildings, it was decided to simulate the building as a stand alone building in open flat area. According to the Uniform Building Code [9], Exposure $\mathrm{C}$ is found to be the most appropriate Exposure to represent the wind pressure on any height. A subroutine was designated to represent the effect of Exposure C. 


\section{The results}

The results of this case study can be capsulated as follows.

- The distribution of the wind pressure on the entire tower is shown in Fig. 2.

- Wind Forces and moments were computed on each ring beam. Figs 3 and 4 illustrate the wind load acting on the first and the last ring beams.

- The average forces and moments acting on the tower as calculated by the numerical simulation are nearly $65 \%$ less than that calculated by the code.

- The maximum suction forces are nearly twice the maximum pressure forces since the maximum pressure stresses acting on the tower varied from $80 \mathrm{~kg} / \mathrm{m}^{2}$ on the lowermost ring beam to $150 \mathrm{~kg} / \mathrm{m}^{2}$ on the uppermost ring beam. While the maximum suction forces located on both sides of the tower areas measured in the radial direction (normal to the tower surface) varied from $170 \mathrm{~kg} / \mathrm{m}^{2}$ on the lowermost ring beam to $340.4 \mathrm{~kg} / \mathrm{m}^{2}$ on the uppermost ring beam.

- The maximum pressure and suction forces are located above the uppermost ring beam as shown in Fig 4.

- If the shear forces were considered in this case study, the total pressure forces acting on the ring beams would increased by about $5 \%$, since the shear forces are acting in the same direction of the wind load.

\section{Analysis of the results}

Different factors lead to nearly $65 \%$ reduction of the pressure forces and the moment acting on the tower calculated by the numerical simulation comparing to those calculated by the code. These factors can be capsulated as follows:

- Due to the circular shape of each ring beam, the total pressure forces are considerably decreased comparing with the code. Where the streamlines of the wind are diverted very smoothly to the new direction as shown in Fig. 5.

- The precisely circular shape in horizontal plane minimizes the fluctuation of the wind pressure on the entire tower. Therefore, the difference between the maximum and the minimum forces acting on any ring beam is insignificant.

- The curved surface in the vertical plane is considered another factor of reducing the average stress on the tower. The wind velocity in the back face of the tower, as shown in Fig. 6, tends to be zero adjacent to the tower and it gradually increases as the point traveled away from the tower as shown in that Figure.

- The maximum positive pressures, which increase the average pressure forces, act on a very tight area, as shown in Figs 5 and 6, where the velocity values reduce to zero (Stagnation point). 
188 Fluid Structure Interaction and Moving Boundary Problems IV

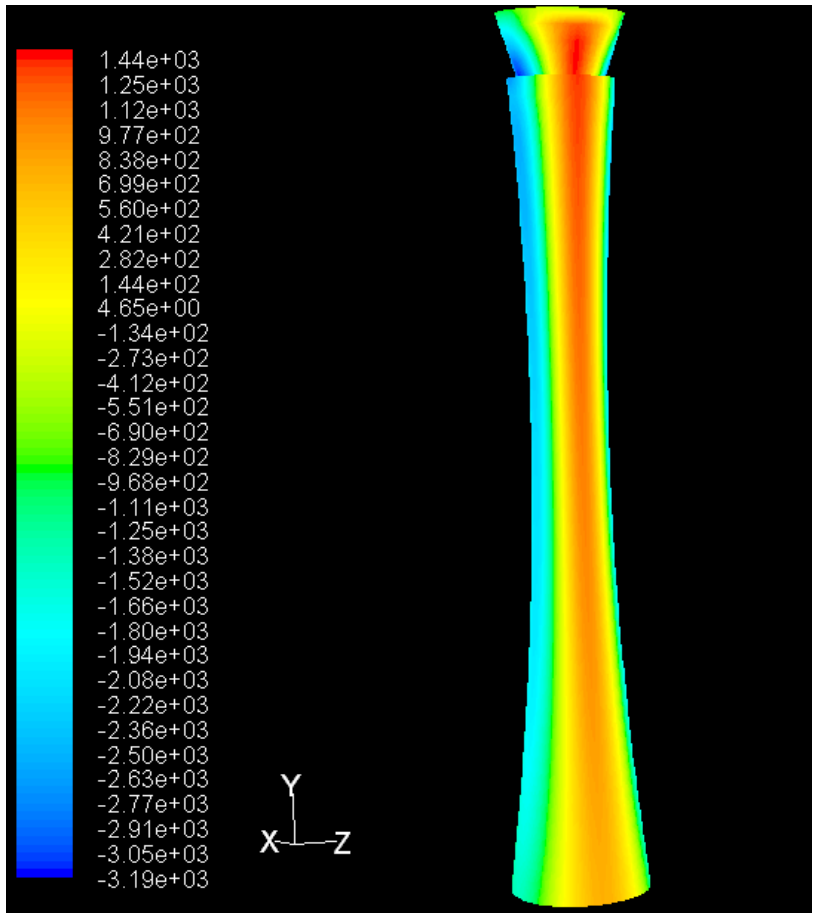

Figure 2: The distribution of the wind pressure (in Newtons) on the entire tower.

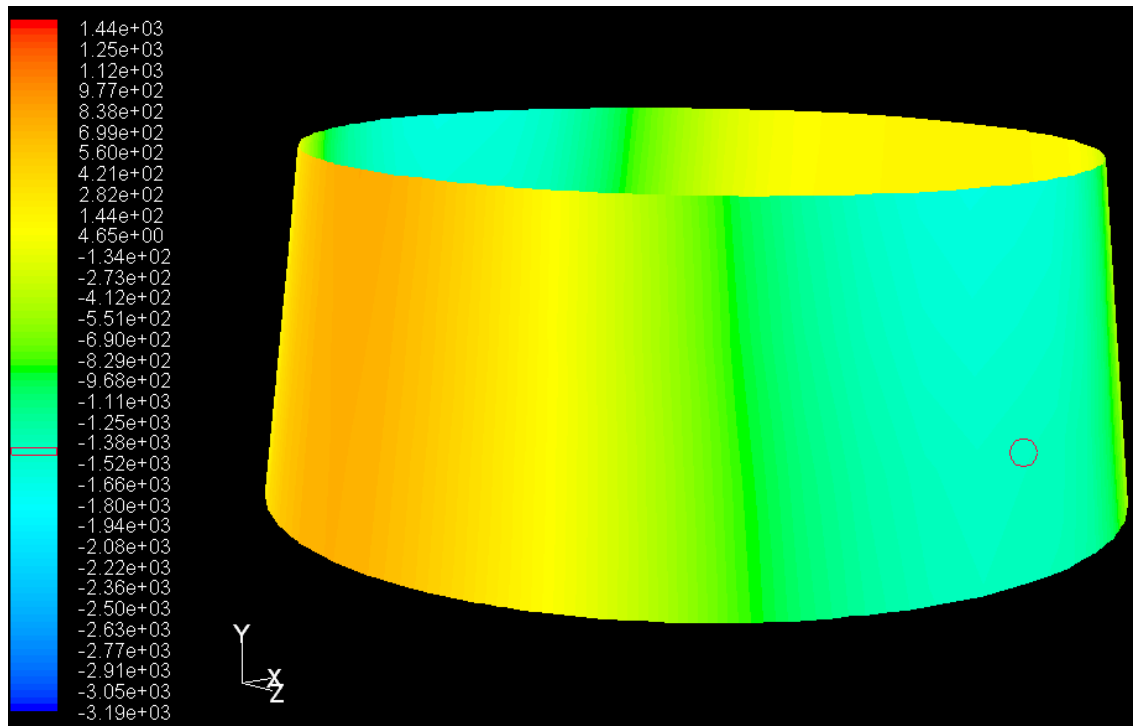

Figure 3: The wind pressure contour (in Newtons) on the lowest " 1 st" ring beam. 


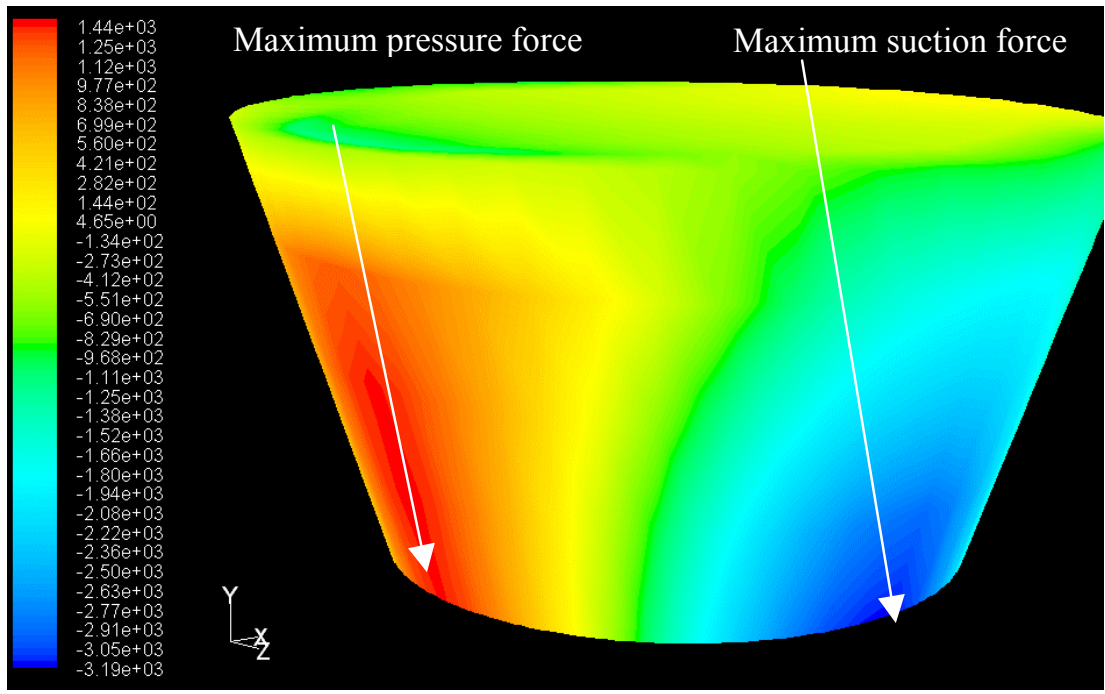

Figure 4: The wind pressure contour (in Newtons) above the highest ring beam.

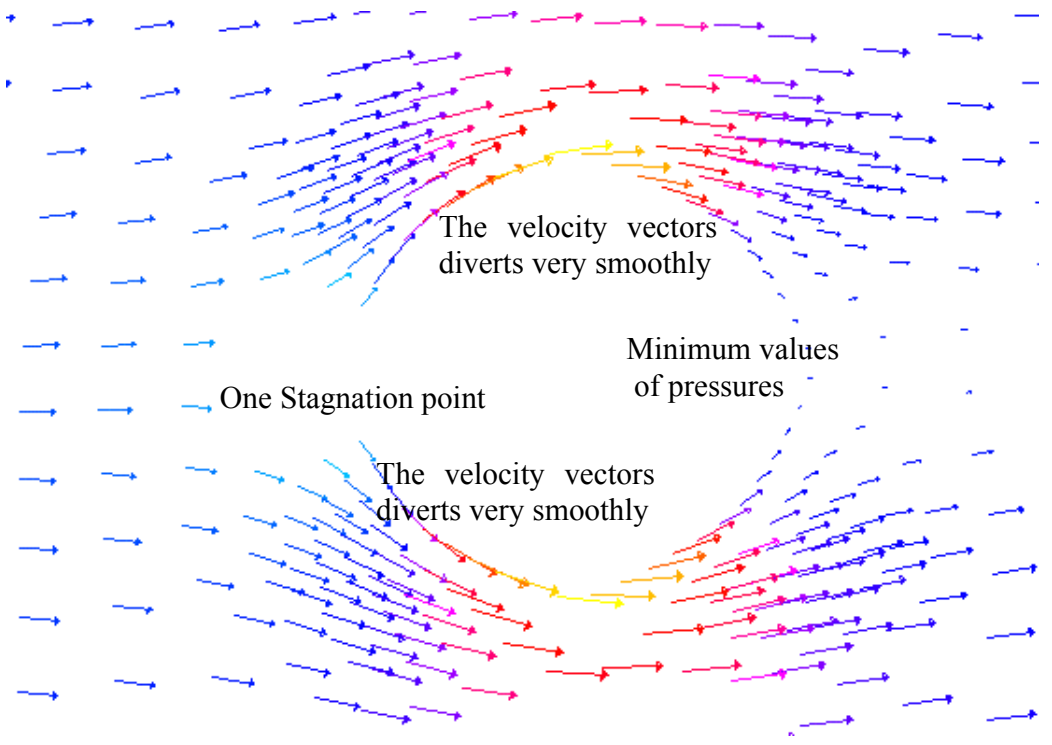

Figure 5: The velocity vector acting on the mid of the tower.

- The actual projected area subject to the positive wind pressure on the front face of the tower is considerably lower than the projected area as shown in Figs 7 and 8 . 
190 Fluid Structure Interaction and Moving Boundary Problems IV

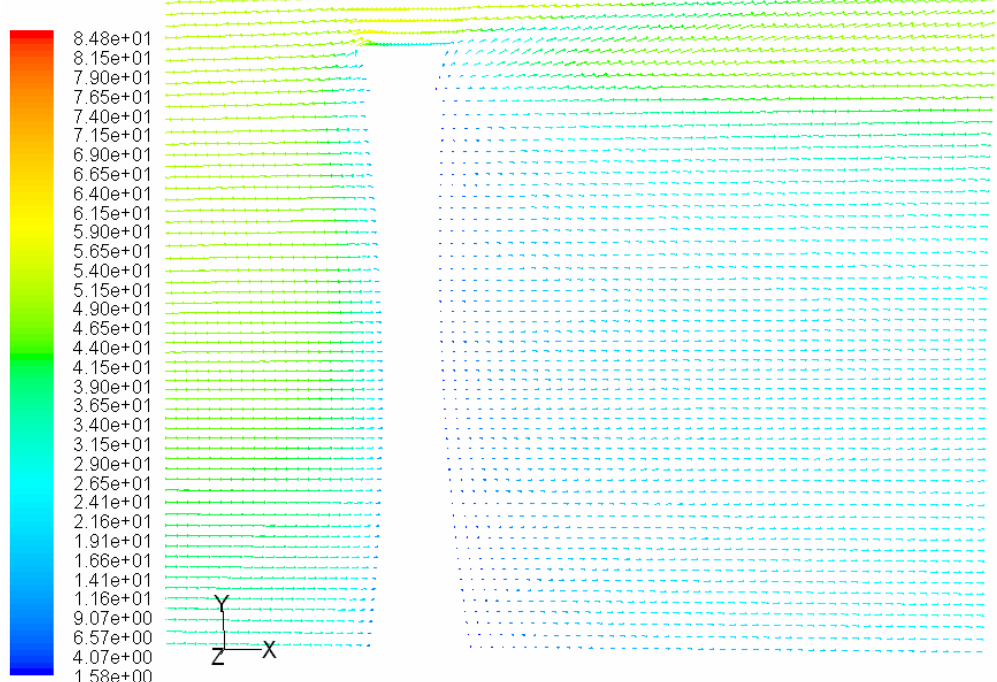

Figure 6: The wind velocity (in $\mathrm{m} / \mathrm{sec}$ ) on the symmetrical vertical plane.

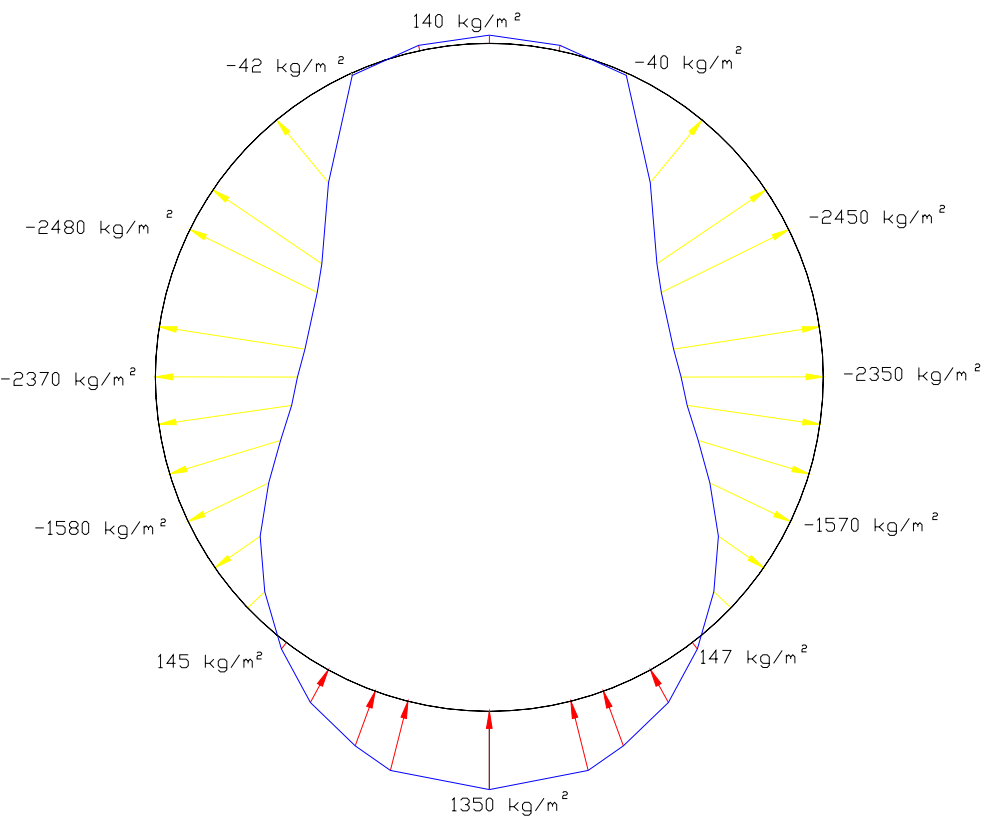

Figure 7: The stress distribution at level $92.05 \mathrm{~m}$ above ground surface. 


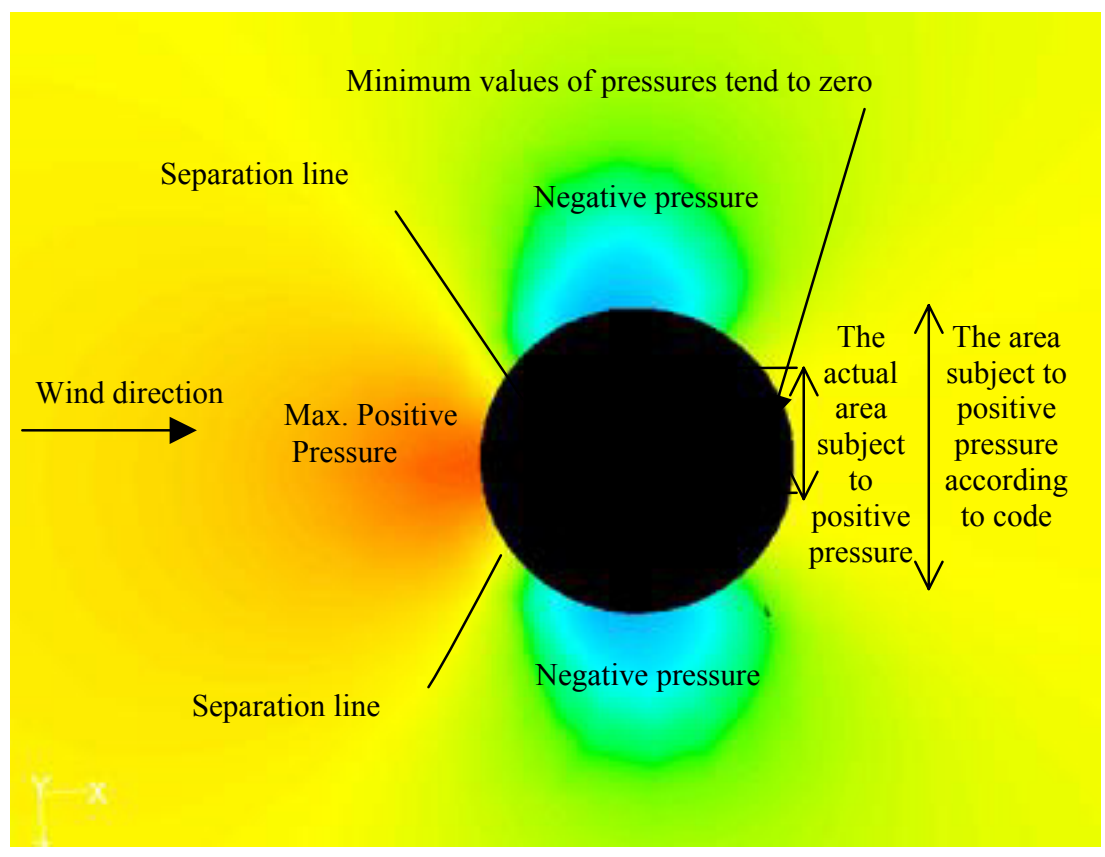

Figure 8: The typical wind pressure contour on horizontal plane.

\section{Summary}

In this research a three-dimensional numerical simulation has been developed using CFD "Fluent" software to study wind effect on the New Cairo Airport Air Traffic Control Tower. All the realistic conditions including the shape of the structure, the wind speed, the wind direction and the wind exposure are precisely considered. The results show that the maximum negative stress, suction, is nearly twice the maximum positive stresses, pressure. In addition the average pressure stress acting on the tower is considerably less than the average pressure forces obtained from the code. Therefore the forces and the moments acting on any ring beam calculated by the numerical simulation are nearly $65 \%$ less than the average pressure forces obtained from the code.

\section{Notation}

$\begin{array}{ll}\text { c } & \text { Speed of the sound. } \\ \vec{F} & \text { The external body forces. } \\ \text { g } & \text { Gravitational acceleration. } \\ \text { I } & \text { The turbulence intensity. } \\ \text { M } & \text { Mach number. }\end{array}$


Sm The mass added to the continuous phase from the dispersed second phase.

P Static pressure

t Time

u Wind speed,

$u^{\prime} \quad$ The root-mean-square of the velocity fluctuations,

$\mathrm{u}_{\text {avg. }} \quad$ The mean velocity.

$\vec{v} \quad$ Overall velocity vector.

$\overline{\bar{\tau}} \quad$ Stress tensor.

$\rho \quad$ Density.

\section{References}

[1] Samali, Kwok, K. C. S., Wood, G.S. \& Yang, J. N., Wind Tunnel Tests for Wind-Excited Benchmark Building, Journal of Mechanical Engineering, Volume 130, Issue 4, Pages 447-450, April 2004.

[2] $\mathrm{Hu}, \mathrm{C}$. \& Wang. F "Using a CFD approach for the study of street-level winds in a built-up area", Building and Environment Volume 40, Issue 5 , Pages 617-631, May 2005

[3] Bitsuamlak, G., T. Stathopoulos, T. \& Bédard, C., Numerical Modeling of Wind Flow over Different Types of Topography, Building on the Past: Securing the Future Structures Congress 2004, George E. Blandford Editor, Nashville, Tennessee, USA, May 22-26, 2004.

[4] Farouk, M. I., Mourad, S., and Salaheldin, A. S., Numerical simulation of wind effects on structures, Scientific Bulletin, Part One, Architectural and Civil Engineering, Ain Shams University, Faculty of Engineering, Cairo, Egypt. Vol. 40, No. 4, page 221, December 31, 2005.

[5] Lina, N., Letchforda, C., Tamurab, Y., Bo Liangc, B., \& Nakamurad, O., Characteristics of wind forces acting on tall buildings, Journal of Wind Engineering and Industrial Aerodynamics Volume 103, Issue 3, Pages 217-242, March 2005

[6] Stathopoulos, T. \& Wu, H., Using Computational Fluid Dynamics (CFD) for Pedestrian Winds", Building on the Past: Securing the Future Structures Congress 2004, George E. Blandford - Editor, Nashville, Tennessee, USA, May 22-26, 2004.

[7] Fluent 6.0 User's guide, Fluent Inc., December, 2001.

[8] Gambit 2.0 User's guide, Fluent Inc., December, 2001

[9] Minimum Design Loads for Buildings and Other Structures, American Society of Civil Engineers, Revision of ASCE 7-108, ASCE STANDARD, 2002. 